\title{
The algorithms for the environmental finance based on adjusted present value models
}

\author{
Oksana Pirogova ${ }^{1}$, Evgeny Gorin ${ }^{2}$, and Vladimir Plotnikov ${ }^{3,4, *}$ \\ ${ }^{1}$ Peter the Great St. Petersburg Polytechnic University, 29, Polytechnicheskaya str., 195251, \\ St. Petersburg, Russia \\ ${ }^{2}$ Institute of Regional Economic Problems of Russian Academy of Science, 38, Serpukhov str., \\ 190013, St. Petersburg, Russia \\ ${ }^{3}$ Saint-Petersburg State University of Economics, 21, Sadovaya str., 191023, St. Petersburg, Russia \\ ${ }^{4}$ South West State University, 94, 50 let Oktiabria str., 305040, Kursk, Russia
}

\begin{abstract}
The article discusses the direction of modification of methods for calculating the optimal capital structure based on compromise theories and, in particular, the method of adjusted cost, which involves taking into account the benefits and costs of debt financing. The tools presented in the article can be used in the practice of environmental financing. The algorithm for calculating the value of the enterprise based on free cash flow is considered, which allows choosing the capital structure from the condition of maximizing the value of the enterprise. The considered theoretical models do not give a complete picture of how to take into account the effect of the tax shield and the possible costs of financial difficulties in making practical decisions related to capital structure. Alternative approaches to the calculation of individual elements and parameters of the method, such as the probability of bankruptcy, are offered. In particular, it was offered to consider logistic regression models for assessing the risk of bankruptcy, as well as to modify the methodology for calculating bankruptcy risk based on a credit rating, taking into account the dependence of the cost of borrowed capital on the level of financial leverage in the enterprise. Further, it is recommended to use a weighted average for the probability of risk of bankruptcy, as well as to carry out adjustment of the value of bankruptcy costs, taking into account the weighted average of the assessment.
\end{abstract}

\section{Introduction}

Today, humanity is faced with a large number of environmental problems. In this regard, there is an active development of the theory of Environmental Science. One of its important directions is the development of new models and tools for environmental finance. Financial management in this area, according to the authors, should be focused not only on achieving positive social and environmental effects. It is also important to ensure the

\footnotetext{
*Corresponding author: plotnikov_2000@mail.ru
} 
economic efficiency of project implementation. Author's research, the results of which are presented in the article, is aimed at solving this actual problem.

The development of information technology, the expansion of the information space opens up new opportunities in the field of business management. Reducing barriers to access to information and to its processing capabilities allows enterprises to use more and more information when making management decisions [1, 2]. New models that use extensive information about the external and internal environment of the company, its history and prospects, the state and prospects of the economy and the industry in which the company operates replace the simple analytical models that use a limited range of indicators. The growth of information about the activities of the company in various aspects increases the awareness of managers and owners of the state of the company. On the other hand, it opens up new opportunities in the access and use of external information, which is also important when making management decisions. This information becomes more voluminous, cheaper, and the efficiency of its receipt is growing all the time. Moreover, with the development of distributed data storage technologies, the possibility of using relevant information in the management of enterprises becomes more and more accessible [3].

The sphere of finance of the enterprise is no exception in this regard. At present, the development of financial models continues, which allow entrepreneurs to answer two basic questions: the first is where and under what conditions (at what price) you can get funds for business development, the second is how to invest these funds in a business in order to increase its efficiency. One of the key issues in the field of enterprise finance is the question of determining the optimal financial structure of an enterprise's capital. Maintaining a rational capital structure on the one hand should help maintain the financial stability and solvency of the company, and on the other, maximize the growth rate of the enterprise's value by reducing the relative amount of cash payments owed to the owners of the company's financial resources.

The use of only internal information about the activities of the enterprise narrows the range of factors that must be considered when determining the optimal capital structure. In this regard, the value of models increases, allowing to determine the optimal capital structure of an enterprise using the full range of information about the enterprise's activities, external information that determines the conditions of the enterprise's activity, as well as macroeconomic and regional forecasts [4]. However, the construction of such models is fraught with certain difficulties, which is primarily due to the large number of correlations between the indicators reflecting the activities of the enterprise. An important factor is also the possibility to take into account in such models a change in the targets and the behaviour of the enterprise at various stages of the life cycle $[5,6]$.

\section{The main approaches to modelling the optimal capital structure based on static models}

Issues of structure management began to be deeply studied during the development of the neoclassical theory of the firm. Numerous classifications of the theory of capital structure identify various areas related to the consideration of certain factors in the preparation of the model. In the theory of capital structure, currently there are two main groups - static theories and dynamic theories.

Static theories include traditional, compromise theories, as well as Miller-Modigliani models, obtained under conditions of stringent restrictions. The most famous group of theories - the compromise theory includes a number of areas in which the costs and benefits of alternative capital structure options are determined when determining the optimal capital structure. 
The first attempt to evaluate the structure of capital was made by Miller and Modigliani [7]. However, the results obtained differed significantly from practice, which required further research in order to remove a number of significant limitations and a higher adequacy of the models to real conditions. It was noted that the endless increase in the share of debt in the capital structure entails an increase in the risk of insolvency and an increase in bankruptcy costs. Thus, the value of a company using borrowed capital and using only equity capital will be correlated as follows [8]:

$$
V_{L}=V_{U}+\tau D_{L}-P V_{B C}
$$

where $\quad V_{L}$ - cost of leverage enterprise;

$V_{U}$ - cost of non-leveraged enterprise;

$\tau D_{L}$ - tax shield benefits;

$P V_{B C}$ - present value of bankruptcy costs.

An alternative approach was proposed in [9] and consists in adjusting the weighted average rate of capital expenditures, into which the premium for the risk of financial problems is introduced. In this case, instead of the traditional formula for the weighted average cost of capital $W A C C$ can be written:

$$
r_{W}=\frac{r_{E} k_{E}+r_{D} k_{D}(1-\tau)+p}{1-p},
$$

where $\quad r_{E}, r_{D}$ - cost of own and borrowed capital in fractions of a unit, respectively;

$k_{E}, k_{D}$ - the share of own and borrowed capital in fractions of a unit, respectively;

$\tau$ - income tax rate in fractions of a unit;

$p$ - bankruptcy risk premium.

The expression can be used to estimate the optimal capital structure, based on the condition of a minimum of the weighted average cost of capital.

\section{Algorithm for determining the optimal capital structure based on static models by the criterion of maximizing the value of the enterprise}

In [10], an algorithm for calculating the capital structure is offered, based on the method of adjusted value, based on the condition of maximizing the value of the enterprise as a discounted free cash flow of the company FCF. The algorithm includes the following steps:

1. Calculating the value of a non-leveraged enterprise based on a cash flow discounting model with a constant growth rate:

2. Assessment of the present value of the benefits of the tax shield, as a product of the tax rate on profits and the amount of borrowed capital

3. Calculating the present value of costs.

The third stage of the algorithm is the most time consuming and requires the involvement of a wide range of data relating to the activities of the enterprise. The paper offers to consider the indirect and direct costs of bankruptcy.

The magnitude of the indirect costs of bankruptcy is usually less than the value of direct costs, and according to expert estimates, it can fluctuate at a level of $2.5-4.0 \%$. The assessment of the direct costs of bankruptcy seems to be more difficult, their assessment 
can be carried out in different ways. As a baseline assessment, it is offered to use the following expression:

$$
P V_{B C}=p \times B C,
$$

where $\quad p$-probability of risk of bankruptcy;

$B C$ - the costs of bankruptcy, or the damage that may arise from the bankruptcy of an enterprise.

The probability of default can be estimated depending on the credit rating of the company. The probability of default depending on the credit rating is presented in Table 1 .

Table 1. The probability of bankruptcy depending on the credit rating [10].

\begin{tabular}{|c|c|}
\hline Credit rating & Probability of bankruptcy, $\%$ \\
\hline AAA & 0.07 \\
\hline AA & 0.51 \\
\hline A + & 0.6 \\
\hline A & 0.66 \\
\hline A- & 2.5 \\
\hline BBB & 7.54 \\
\hline BB & 16.63 \\
\hline B + & 25.0 \\
\hline B & 36.8 \\
\hline B- & 45.0 \\
\hline CC & 59.01 \\
\hline CC & 70.0 \\
\hline C & 80.0 \\
\hline D & 100.0 \\
\hline
\end{tabular}

The second approach is to use a statistical approach based on binary or logistic regression models. This approach was considered in [11], and offered by A. Damodaran. The use of the logistic regression method (logit model) $[12,13]$ seems promising due to the fact that, on the one hand, it is based on statistical data, and, on the other hand, it provides an estimate of the probability of bankruptcy risk. J.A. Olson first offered this model [14].

According to this model, the probability of bankruptcy of an enterprise is determined based on the ratio:

$$
p=\frac{1}{1+e^{-Y}},
$$

where $\quad p$ - probability of bankruptcy;

$e$ - Euler number;

$Y$ - logistic regression indicator.

In the general case, the logistic regression indicator is calculated based on:

$$
Y=A-B_{1} X_{1}-B_{2} X_{2}-\ldots-B_{n} X_{n},
$$

where $\quad A, B_{i}$ - model coefficients;

$X_{i}$ - model factors;

$n$ - number of model factors.

Thus, Olson obtained a nine-factor model, which includes nine different financial indicators, sometimes exotic, which are practically not found in the domestic financial and economic analysis, for example, the ratio of total assets to the deflator index of the gross national product.

In our country, V. Zhdanov built a five-factor logistics model for assessing the 
probability of bankruptcy of enterprises in the aviation industry [15]. Separately, it should be noted ten-factor model offered by A. Haydarshina, which offered coefficients for enterprises of various industries [16].

Unlike discriminant models (MDA, for example, Altman models), the logit model allows us to make a conclusion not only about the enterprise's membership in the bankrupt group (which limits the interpretation of MDA models), but also to estimate the likelihood of bankruptcy risk for the enterprise, as well as to describe nonlinear dependencies between variables in the model.

Among the advantages of logit-models, the authors of [13] note the following:

- Ability to determine the risk of bankruptcy of an enterprise.

- Sufficiently high accuracy of the results.

- Opportunity to take into account the industry-specific activities of enterprises.

- Soft requirements for normal input data, compared with MDA-models.

- Ease of interpretation of results for enterprise management.

As a rule, these models include indicators reflecting the capital structure, for example, the Zhdanov model includes a self-financing ratio, and the Olson model includes the ratio of total liabilities to total assets.

Russian researchers offer the third approach. Therefore, T.V. Teplova, A.S. Getalova [17], the team of researchers at the Corporate Finance Laboratory of the Higher School of Economics [18], suggests that the present value of the costs of financial instability be calculated as the product of the probability of default and two standard deviations of operating profit (EBIT).

$$
P V_{B C}=2 \sigma_{E B I T}
$$

At the same time, it should be noted that the approach considered in [9, 10] does not take into account a number of features. It is known that the estimated company already has a certain structure of sources of financing. Consequently, if, when searching for the optimal capital structure, we begin to deviate from the already established capital structure, the credit rating of the enterprise will also change, as well as the interest rate on borrowed capital. Unfortunately, these aspects are not reflected in the developed models. The following is an approach to consider the features.

The simplest ways to assess the impact of borrowed capital on the activities of an enterprise are such indicators as the degree of the impact of financial leverage (DFL), as well as the coverage ratio (ICR). The economic meaning of the impact of financial leverage lies in the fact that it shows how much the company's net profit increases when the value of operating profit changes by one percent. DFL is calculated using the expression:

$$
D F L=\frac{E B I T}{E B I T-I n}
$$

where $\quad E B I T$ - operating profit;

EBIT - In - taxable profit;

In - amount of interest on loans or borrowings.

In accordance with this indicator, by an increase in borrowed capital, debt-servicing costs increase, which leads to an increase in DFL.

The interest coverage ratio shows the company's ability to service the debt and shows how many times the amount of operating profit exceeds the amount of interest on loans or borrowings that the company pays: 


$$
I C R=\frac{E B I T}{I n}
$$

A synonym for ICR in investment practice is TIE (time interest earned). The ICE value is an indicator of the measure of meeting the obligations of an enterprise and the level of debt service security. This indicator is used to assess the quality of the borrower. However, these indicators cannot be fully used in assessing the optimal level of borrowed capital because a significant number of factors influences this parameter.

It is offered to evaluate the credit rating of an enterprise based on the value of the interest coverage ratio. It should be noted that the amount of interest on loans itself also depends on financial leverage.

First, calculate the ratio of borrowed and equity capital.

Second, take into account the effect of the share of borrowed capital on the cost of its attraction. To do this, you can use single-factor or multifactor equations derived from regression dependencies, for example, the type dependencies presented in [19]:

$$
r_{D}=0,099+0,008 \frac{D}{E B I T D A},
$$

where $\quad D$ - enterprise debt;

EBITDA - earnings before interest, taxes and depreciation.

Further, it becomes possible to assess the risk of bankruptcy, taking into account the modified approach. The amount of interest on the loan is determined in accordance with the established amendments to the capital structure.

After that, based on the relationship of the credit rating to the expense coverage ratio, the rating is determined, and further, using the scale presented in Table 1, the amount of risk is determined.

Table 2. The relationship of the credit rating of the enterprise with the cost recovery ratio and the level of financial leverage [20].

\begin{tabular}{|c|c|c|c|}
\hline \multicolumn{2}{|c|}{ For large enterprises } & \multicolumn{2}{c|}{ For small enterprises } \\
\hline Interest coverage ratio & Rating & Interest coverage ratio & Rating \\
\hline$<0.2$ & D & $<0.2$ & D \\
\hline $0.2-0.65$ & C & $0.2-0.65$ & C \\
\hline $0.65-0.8$ & CC & $0.65-0.8$ & CC \\
\hline $0.8-1.25$ & CCC & $0.8-1.25$ & CCC \\
\hline $1.25-1.5$ & B- & $1.25-1.5$ & B- \\
\hline $1.5-1.75$ & B & $1.5-1.75$ & B \\
\hline $1.75-2$ & B + & $1.75-2$ & B + \\
\hline $2.25-2.5$ & BB & $2.25-2.5$ & BB \\
\hline $2.5-3$ & BBB & $2.5-3$ & BBB \\
\hline $3-4.25$ & A- & $3-4.25$ & A- \\
\hline $4.25-5.5$ & A & $4.25-5.5$ & A \\
\hline $5.5-6.5$ & A+ & $5.5-6.5$ & A+ \\
\hline $6.5-8.5$ & AA & $6.5-8.5$ & AA \\
\hline$>8.5$ & AAA & $>8.5$ & AAA \\
\hline
\end{tabular}

Another point of the offered modified methodology is what the optimal level of debt to determine is.

The first approach involves determining the limits of optimal borrowing at the enterprise, i.e. answer to the question how much a company can borrow. At the same time, the own capital of the enterprise is fixed, and the amount of borrowed capital varies. At the same time, there is one important amendment here; the size of the capital involved or 
invested must remain unchanged. The fact is that an increase in the invested capital can significantly affect the required volumes of revenue, which is not always possible due to, for example, limited market volumes, or antitrust restrictions, etc.

The second approach involves the selection of the optimal capital structure of a given size. In this case, the problem is solved, how to change the structure of capital without changing the capitalization. Obviously, both the first and second approaches can be used in predicting the optimal capital structure, while the first approach should be used when the company's growth is fast enough and borrowing is required to ensure it. The second approach should be used when the volume of activity and the market niche of the enterprise is fixed, while optimization of activity can be carried out by selecting the optimal capital structure.

\section{Conclusion}

Thus, the offered approach makes it possible, in addition to the tax shield, to take into account the impact of bankruptcy costs in the form of a change in the current value of an enterprise's leveraged cash flow. This will allow the company to reduce the risk of bankruptcy and the amount of possible loss and correctly form the capital structure. The offered model is based on the use of a wide range of statistical and aggregated economic data, which can be refined in the activity process of both the enterprise itself and changes in the economic situation in the industry and in the economy as a whole. At the same time, it is offered to use more widely weighted average estimates of indicators for which calculation is possible using various methods.

According to the authors, the developed capital management tools presented in the article can be used in the practice of environmental financing, in the implementation of projects in various fields (garbage processing, green energy, etc.) [21, 22]. Described in the article innovative algorithms for the environmental finance is recommended for use when justifying projects at the micro level. It allows you to perform optimal capital structure determining based on adjusted present value models.

\section{Acknowledgements}

The paper is an output of the science project of the government task of Ministry of education and science of the Russian Federation \# 26.3546.2017/PCH "Development fundamentals of analysis and prediction of structural and dynamic parameters of the regional economy are based on the integration of the Russian and world experience of management of territorial development and modern scientific doctrines".

\section{References}

1. E.J. Malecki, B. Moriset, The digital economy: Business organization, production processes and regional developments (Routledge, London, 2007)

2. D. Helbing, Thinking ahead-essays on big data, digital revolution, and participatory market society (Springer, 2015)

3. S. Graham, D. Wood, Critical Social Policy 23(2), 227-248 (2003)

4. M. Harris, A. Raviv, Journal of Finance 45, 321-349 (1990)

5. V. Plotnikov, O. Pirogova, Proceedings of the 31st International Business Information Management Association Conference (IBIMA), 1716-1721 (2018) 
6. O. Pirogova, V. Plotnikov, A. Prolubnikov, SHS Web of Conferences 44, 00071 (2018) DOI: $10.1051 /$ shsconf $/ 20184400071$

7. F. Modigliani, M. Miller, American Economic Review 53, 433-443 (1963)

8. A. Kraus, R.H. Litzenberger, Journal of Finance 28, 911-922 (1973)

9. A. Pilyugina, Vestnik MGTU im. N.E. Bauman. Ser. "Natural Sciences" 6, 140-154 (2012)

10. A. Zadorozhnaya, Finance and Credit 7, 34-44 (2015)

11. A. Damodaran, Applied Corporate Finance (Wiley, 2010)

12. V. Sokolov, Mathematical modeling in economics and management 1, 67-73 (2006)

13. O. Pirogova, Izvestia of St. Petersburg State University of Economics 1(91), 26-32 (2015)

14. J.A. Ohlson, Journal of Accounting Research 18, 109-131 (1980)

15. V. Zhdanov, O. Afanasyeva, Journal of Corporate Finance Research 5(4), 77-89 (2011) DOI: 10.17323/j.jcfr.2073-0438.5.4.2011.77-89

16. G. Khaidarshina, Property relations in the Russian Federation 8(95), 86-95 (2009)

17. T. Teplova, A. Getalova, Corporate Finance Management 5, 262-279 (2013)

18. I. Anyukhina, I. Ivaninskii, E. Kataeva, O. Ozornina, D. Serebryanskii, M. ShmidtRost, Journal of Corporate Finance Research 4, 88-105 (2008) DOI: 10.17323/j.jcfr.2073-0438.2.4.2008.88-105

19. T. Teplova, T. Sokolova, Corporate Finance Management 5(47), 198-220 (2011)

20. L. Laskina, G. Kalvarsky, Financial Analytics: Problems and Solutions 13, 16-25 (2016)

21. Y. Vertakova, M. Klevtsova, T. Babich, Economic Annals-XXI 157(3-4), 4-7 (2016) DOI: 10.21003/ea.V157-0001

22. Y.V. Vertakova, T.N. Babich, Y.S. Polozhentseva, G.L. Zvyagintsev, IOP Conference Series: Earth and Environmental Science 87(9), 092031 (2017) DOI: 10.1088/17551315/87/9/092031 